\title{
Identification and binomial computerization of plant species
}

\author{
K. Karthik ${ }^{1}$, M. Pugalenthi ${ }^{2}$, P. S. Sharavanan ${ }^{1, *}$ \\ ${ }^{1}$ Department of Botany, Annamalai University, Tamil Nadu, India \\ ${ }^{2}$ Department of Botany, Government Arts College, Coimbatore, Tamil Nadu, India \\ *E-mail address: drpssharavanan@yahoo.co.in
}

\begin{abstract}
The binomial computerization method is comparison of certain similarities and differences of plants identification system. The ultimate purpose of the plants identification process is method of using digital tools of database and creating new version of plants identification for constructing the digital keys. The present study of plant identification system is based on computerization processes. The plants species characters are constructing basis on taxonomical literature and followed by suitable classification system and binomial rules.
\end{abstract}

Keywords: Binomial; Computerization; Digital tools; Plants identification; Computerization processes; New technology

\section{INTRODUCTION}

Identification is a basic activity and one of the primary objectives of systematic. Although identification is a separate activity or process, (Black welder, 1967 ) in practice it involves both classification and nomenclature. Present computerization study is based on Bentham and Hooker classification system (Pandey B. P., 2009). Identification is simply the determination of the similarities or differences between two elements. The two elements are the same or they are different. The comparison of an unknown plant with a named specimen and the determination that the two elements are the same also involves classification. When one correctly decides that an unknown belongs to the same group (family, genus, species, etc.) as a known specimen, the information stored in classification systems becomes available and applicable to the material at hand. Both processes of identification and classification involve comparison and judgment requires a definition of criteria of similarities. Identification is therefore a basic process in classification with nomenclature playing an essential role in the retrieval of information and as a means of communication. Identification of species is based on traditional, paper printed keys that comprises a series of questions, answers to which lead to the name of the species. Answers can be found by careful investigation of the characters of the specimen that one wants to identify. However, these keys have several drawbacks that have made the process of identifying species a boring and complicated one. The computerized keys are a device is by far the most method and does not require the time, materials or experience involved comparison and recognition. The Present study is completely based on computerized keys (PHP Program). Keys are devices 
consisting of a series of contrasting or contradictory statements or propositions requiring the identifier to make comparisons and decisions based on statements in the computerized key as related to the materials to be identified. The computerized plant keys are much faster and easier to use than traditional plant identification system.

\section{METHODOLOGY}

\section{1. Expert determination}

In terms of reliability or accuracy the best method of identification is expert determination. (Morse (1971) In general the expert will have prepared treatments of the groups in question and it is probable that more recent floras or manuals include the expert's concepts of taxa. The great reliability, this method presents problems by requiring the valuable time of experts and creating delays for identifications.

\section{2. Recognition}

According to (Morse, 1971) approaches expert determination in reliability. This is based on extensive, past experience of the identifier with the plant group in question. In some groups of this system is virtually impossible.

\section{3. Comparison}

Comparison of an unknown with named specimens, photographs, illustration or description. Even though this is a reliable method, but virtually impossible due to the lack of suitable materials for comparison.

\section{4. Computational system}

Computational system is a general approach towards the solution of scientific problems through which advanced computational techniques are used to discover the hidden order in complex data sets of plant systematic and to decipher the languages of biology (Amalkumar Mondal, 2009). Modern taxonomist used the database technologies to search and catalog classification, data base such as the attempts to list of every documented species.

\section{5. Computerization}

The control of processes by computer based keys are devices consisting of a series of contrasting or contradictory statements or propositions requiring the identifier to make comparisons and decisions based on statements in the key as related to the material to be identified based on using compute. The present study is based on plant identification for using compute, following evidence of computerized HTML page of plant species and type of programs noted in below. [Keys, Families, Monocotyledons, Dicotyledons], study materials of selected plant keys are taken from the source of Gamble (Gamble, 1915-1936). 
No. of keys contracted: 15[HTML]

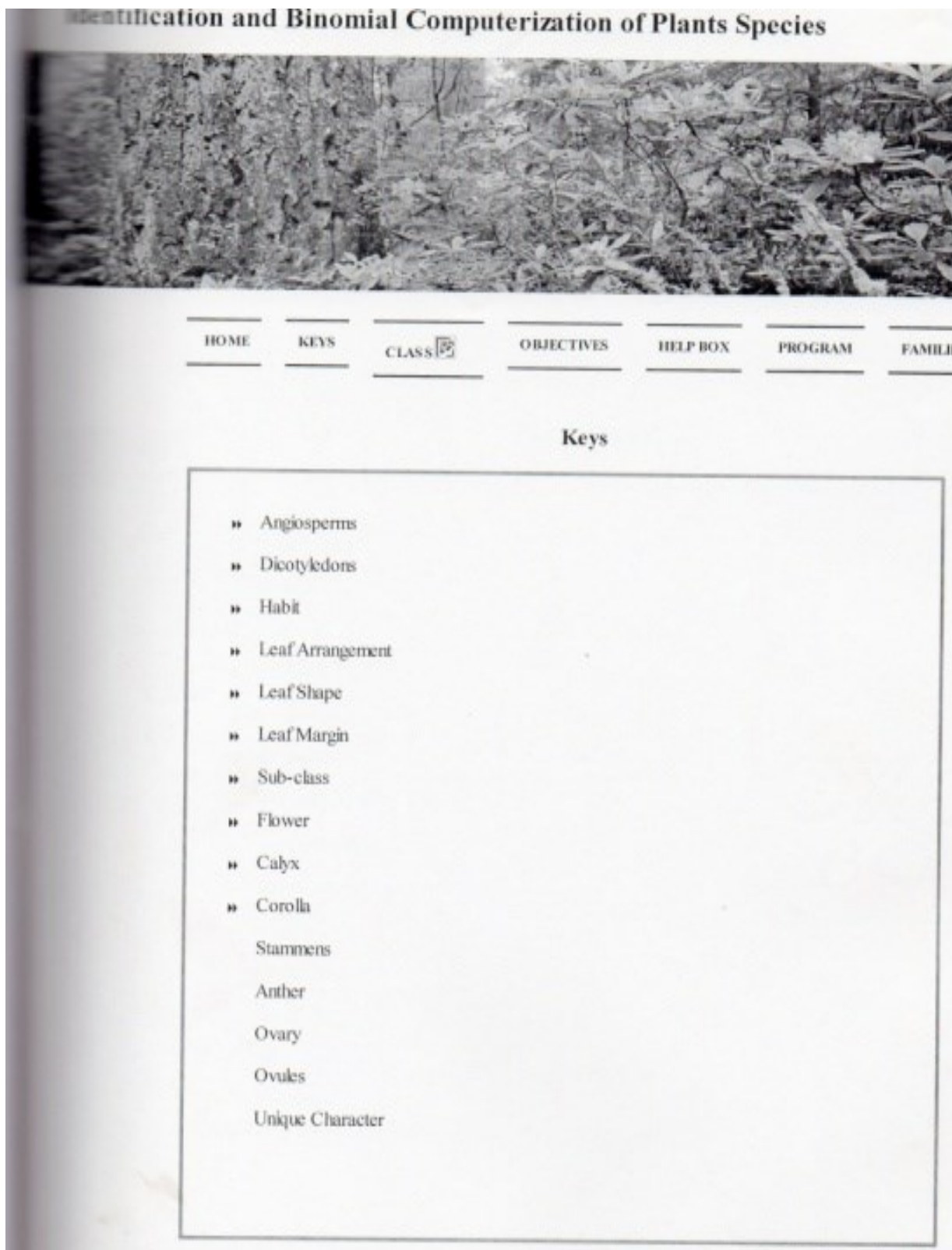


Computerized families: 14 [HTML]

:: Identification and Binomial Comput...

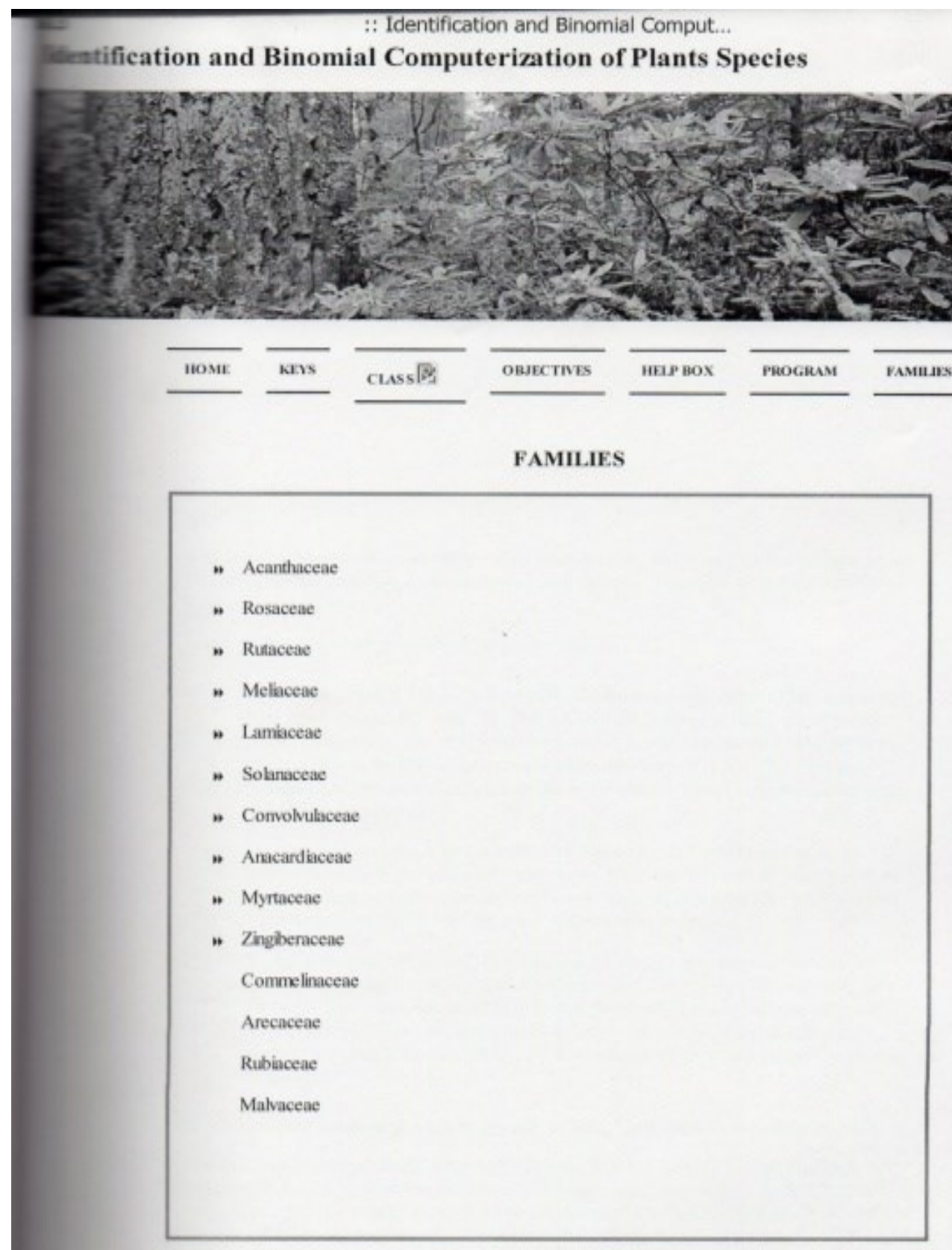




\section{PROGRAM}

PHP[Server-Side Scripting], so user can do anything any other CGI program can do, such as collect from data, generate dynamic page content(web page development) or send scientific information in the form of web page. But PHP can do much more. There are three main areas where PHP scripts are used. PHP can be used on all major operating system, including Linux, Unix variants, HP-UX, Solaris and open BSD, Mac OSX, RISC OSX,HTML, XHTML and XML. Major three given in below,

- Server-side scripting [CGL-Server module]

- Command line scripting [PHP-Linux]-[HTML]

- Writing desktop application scripting [PHP-GTK]

\section{RESULTS}

\section{Dicotyledons HTML Page}

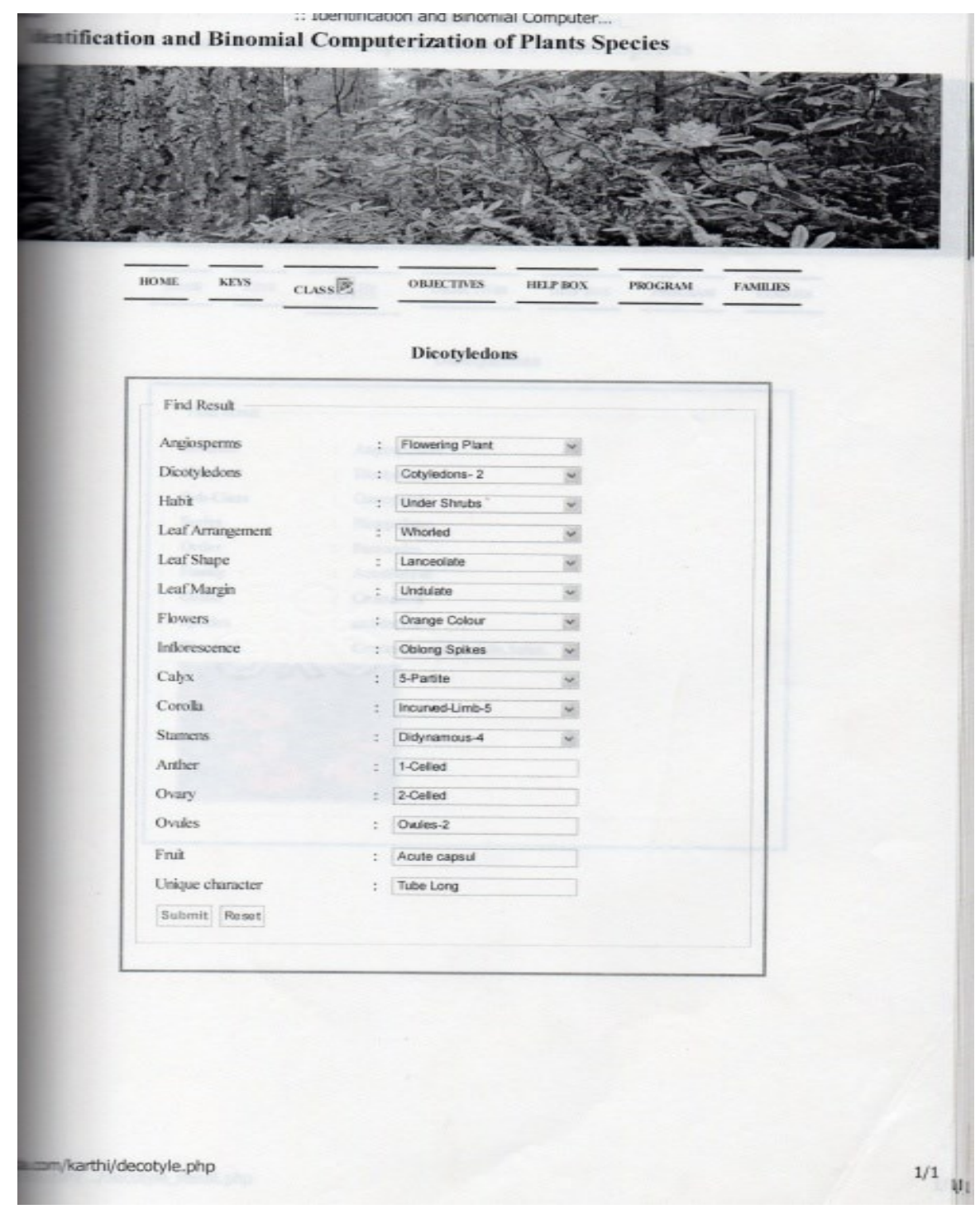




\section{Submitting result of plant}

:: Identification and Binomial Computeri...

feation and Binomial Computerization of Plants Species

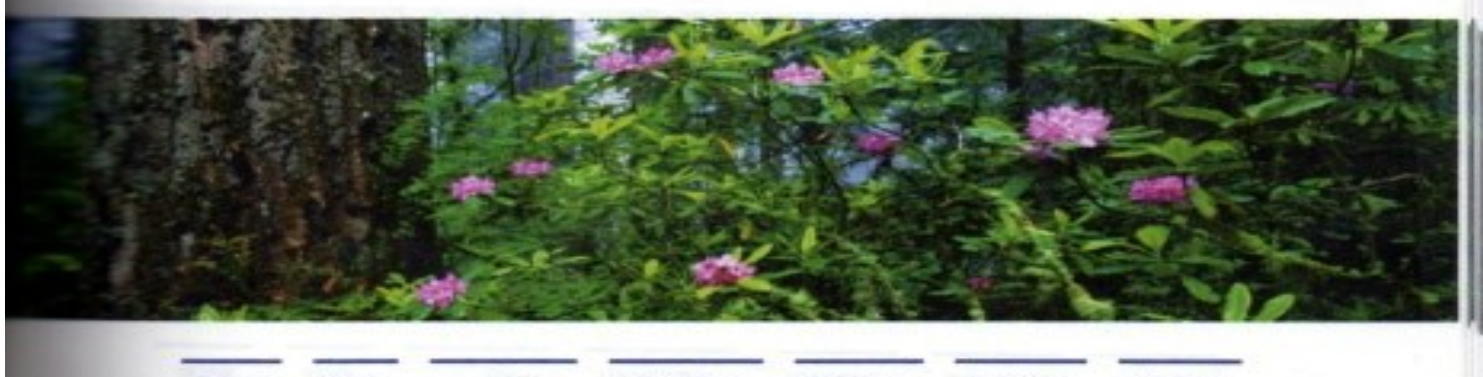

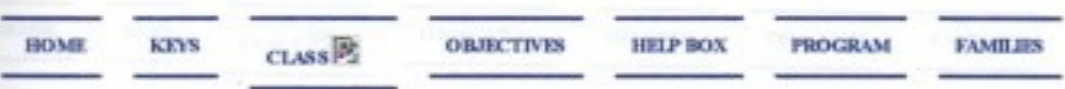

Dicotyledons

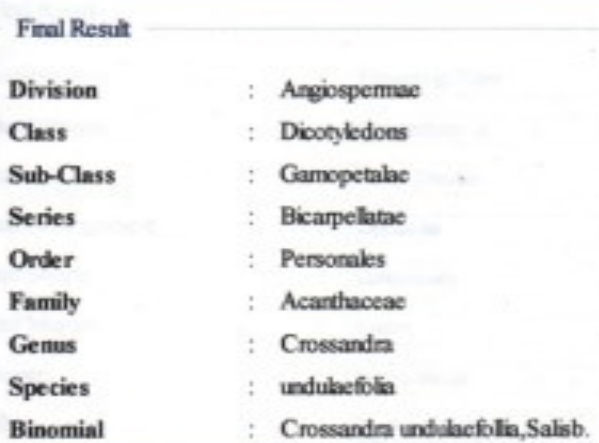
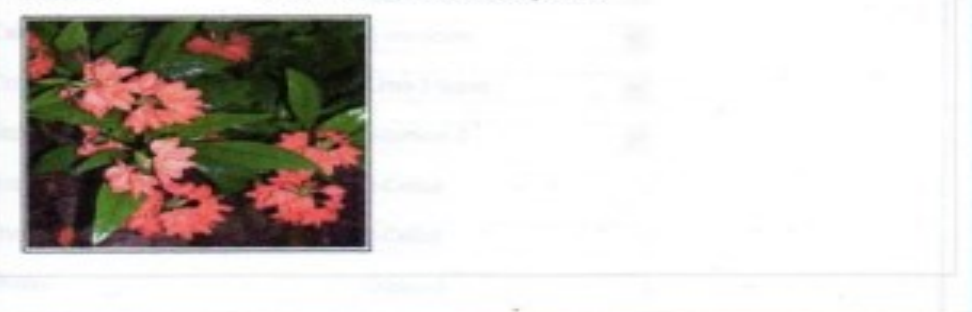


\section{Monocotyledons [HTML] Page}

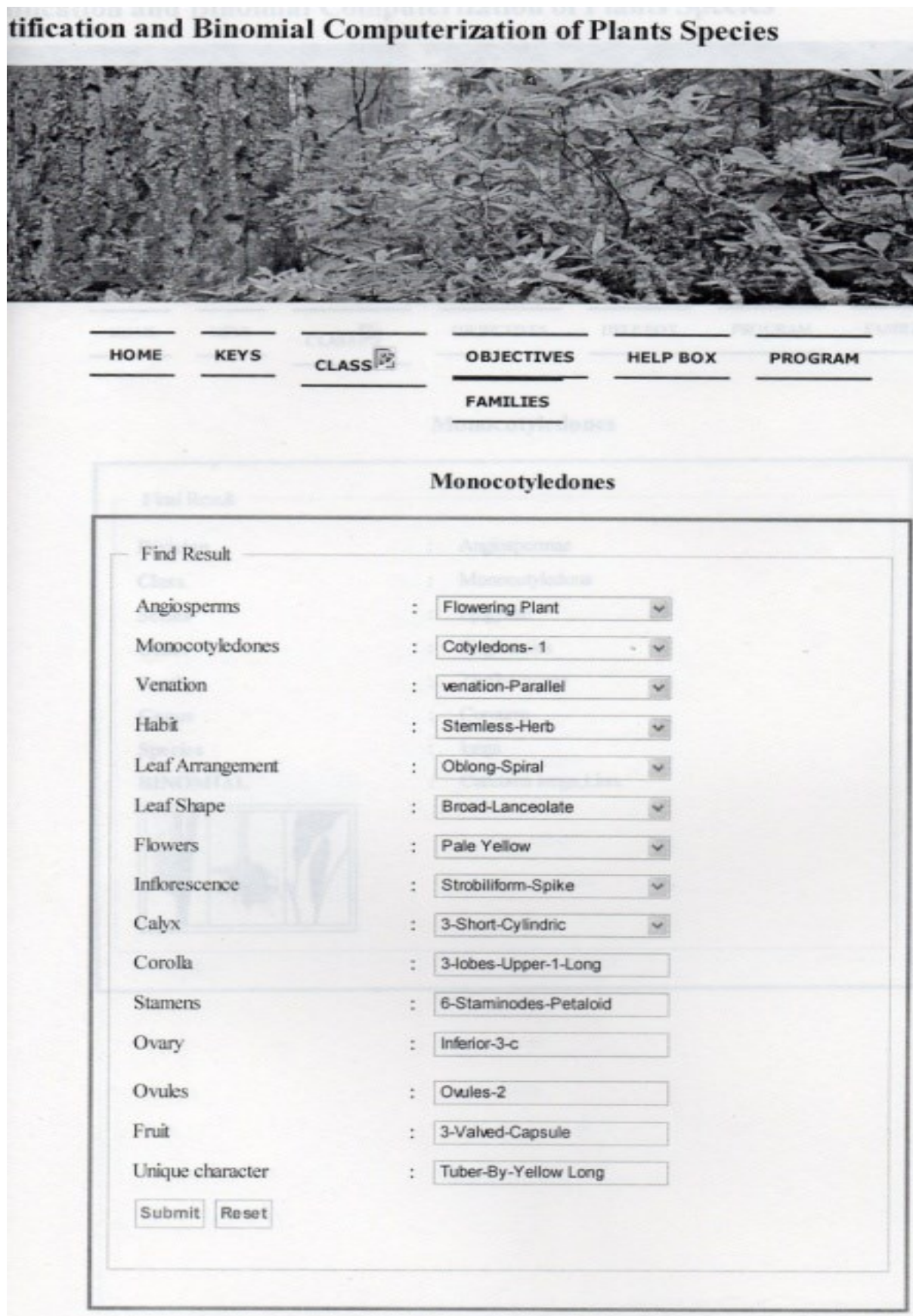




\section{Submitting result of plant}

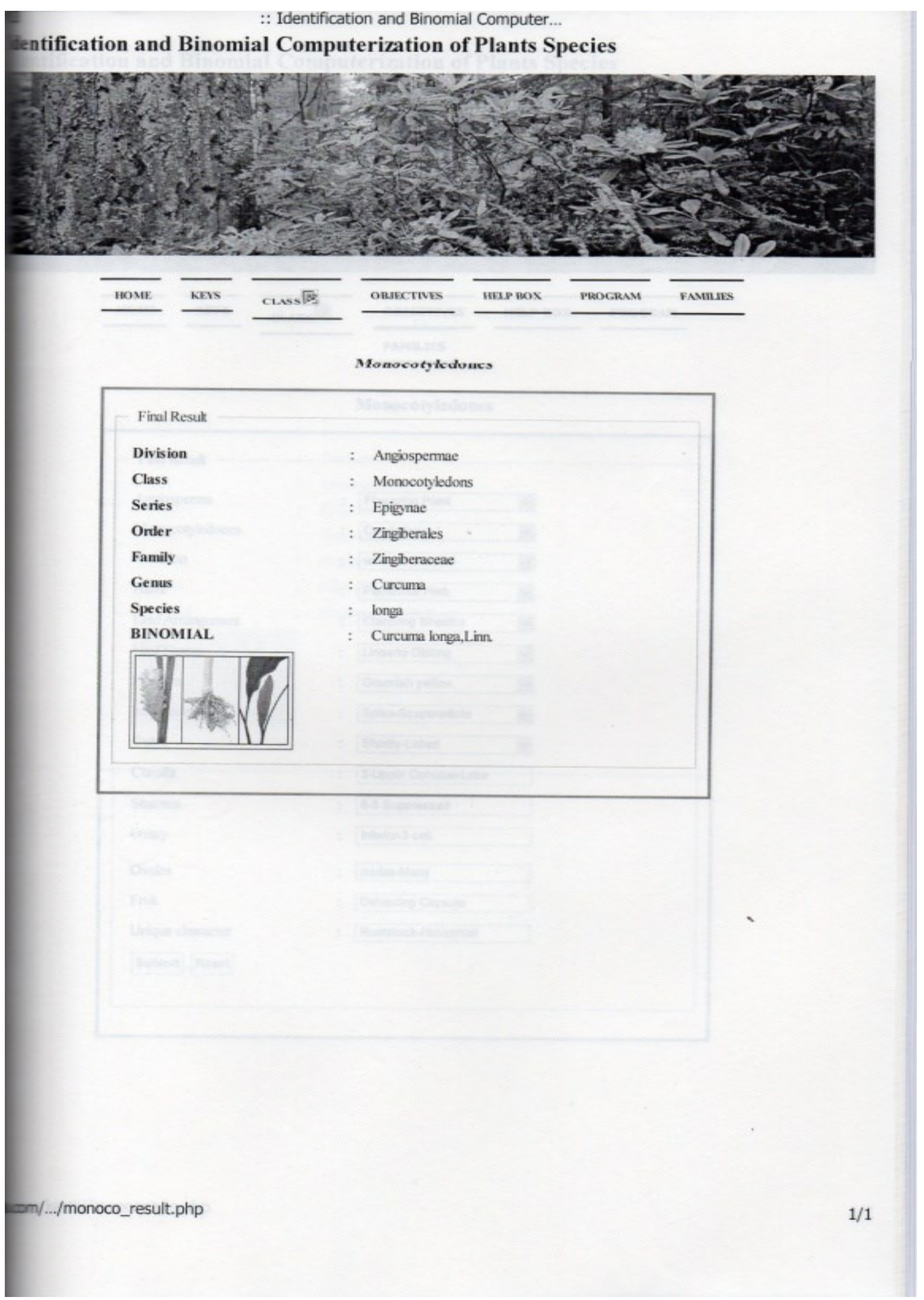




\section{CONCLUSION}

In the present study, due to time constraints, 20 plants were selected and has developed computerization methodology through software based data base system. Future studies are required to develop computer software based identification system which will enable even a non-botanist with little knowledge on plants are also able to identify the plants species. And this is the need of work since, experts in plants identification is drastically decreasing, due to the development of modern biology. Old method of plants identification system is not truly judged the plants name because lack of plant taxonomist in biological science. In the present study of computerization process is valuable, faster and easily to use, than traditional system of plants identification. The ultimate purpose of the present study is using digital tools of computerization database and creating new version of plants identification system.

\section{References}

[1] Amal Kumar Mondal (2009) Text book of advanced plant taxonomy, New Central Book Agency (P) LTD.

[2] Blackwelder (1967). "Identification enables us to retrieve the appropriate facts from the System (Classification) to be associated with some specimen " and is better description as the recovery side of taxonomy.

[3] Gamble J. S., C. E. C. Fisher (1915-1936). Flora of the Presidency of Madras II Parts.

[4] Gamble J. S., (1878). List of trees, Shrubs and Large climbers found in the Darjeeling District, Bengal,Calcuta.

[5] Morse (1971). Approachment of expert determination system in plants Identification 1 volume.

[6] Pandey B. P. (2009). Text book of taxonomy of angiosperms, 1 volume, S.Chand \& Company (P) LTD.

[7] Maheswari P., R. N. Kapil, (1963). Fifty years of science in India: Progress of Botany, Ind. se. cong. Assn., Calcata.

[8] Pandey B. P. (2009). Taxonomy of Angiosperms, 1 volume, S. Chand \& Company (P) LTD

[9] Puri V. (1952). Floral Anatomy in Relation to Taxonomy, Agra Univ. J. Res. Sci. 1; $15-35$

[10] Sporne K. R. (1956). The phylogenic classification of the Angiosperms, Biol. Rev., 31; $1-29$. 